\title{
Comparison between volume-controlled and pressure-controlled ventilation in COPD patients undergoing laparoscopic cholecystectomy
}

Mohamed A. Zaghloul, Samir A. El-Sebaie, Azza A. Abd Al-Alim, Abdel Rahman M. El-Sotouhy

Anesthesiology, Intensive Care and Pain Management Department, Faculty of Medicine, Ain Shams University

\begin{abstract}
Background: Chronic obstructive pulmonary disease (COPD) is a well-known independent risk factor for the development of postoperative pulmonary complications. Managing ventilation and oxygenation during laparoscopic cholecystectomy (with creation of pneumoperitoneum) in these patients presents many challenges.

Aim of this study: was to compare between volume-controlled and pressure-controlled ventilation in COPD patients undergoing laparoscopic cholecystectomy.

Methods: A case control study was conducted on 60 participants aged between 18 and 60 years, diagnosed with COPD and scheduled for laparoscopic cholecystectomy. To start with, all patients received volumecontrolled ventilation (VCV). Fifteen minutes after creation of pneumoperitoneum, they were randomized to receive either VCV (Group A) or pressure-controlled ventilation; PCV (Group B). Hemodynamics, ventilatory parameters, arterial blood gas analyses were noted. All data were analyzed statistically.

Results: There was no significant difference between study groups as regards hemodynamic variables. Peak airway pressure was significantly lower in PCV group compared with VCV group. Mean airway pressure was significantly higher in PCV group compared with VCV group. As regards arterial blood gas analyses, there was no significant difference between study groups as regards $\mathrm{PaO} 2$ and $\mathrm{SpO} 2$. Patients in $\mathrm{PCV}$ group had higher PaCO2 (yet not clinically significant) at $35 \mathrm{~min}$, compared with patients in VCV group.

Conclusion: PCV and VCV were generally effective in maintaining adequate ventilation, oxygenation and hemodynamic stability. Peak airway pressure was significantly lower in PCV group compared with VCV group, thus decreasing the risk of barotrauma. PCV may be a better choice than VCV in COPD patients undergoing laparoscopic cholecystectomy.
\end{abstract}

Key words: Laparoscopic cholecystectomy, chronic obstructive pulmonary disease, pressure-controlled ventilation، volume-controlled ventilation.

\section{INTRODUCTION}

Chronic obstructive pulmonary disease (COPD) is a well-known independent risk factor for the development of postoperative pulmonary and cardiac complications after thoracic or nonthoracic surgery ${ }^{1}$.

Laparoscopic cholecystectomy is considered to be the gold standard for laparoscopic surgical procedures ${ }^{2}$. During laparoscopy, the peritoneal space is insufflated with gas and this pneumoperitoneum may result in intraoperative atelectasis, which impairs normal gas exchange ${ }^{3}$. In patients with concomitant pulmonary diseases, creation of pneumoperitoneum and patient's position during surgery exert additional negative effects on intraoperative pulmonary function, which makes a higher challenge for the anesthesiologist than for the surgeon ${ }^{2}$.

The use of volume-controlled ventilation (VCV) is common, as this has been the only available mode on ventilators for a long time. This mode ensures satisfactory minute ventilation, but can lead to higher pressure levels ${ }^{4}$.

Developments in our understanding of pressure-volume curves and the demonstration of microscopic shear stress lung injury have changed the whole concept of safe ranges of pressure and volume in mechanical ventilation 5 . Ventilatory parameters must be adjusted to overcome the respiratory consequences of pneumoperitoneum such as elevated peak and plateau airway pressure and decreased dynamic compliance of the respiratory system ${ }^{6}$.

Several ventilatory strategies have been proposed to prevent intraoperative atelectasis and improve arterial oxygenation in laparoscopic surgeries but they remain controversial. Pressurecontrolled ventilation (PCV) can be used in the management of patients with elevated peak airway pressures, which occurs with pneumoperitoneum ${ }^{7}$.

During PCV, pressure limits and uniform distribution of forces within the lung reduce the risk of volutrauma and barotrauma. Characteristics of PCV tend to compensate for any potential reduction in ventilation caused by pressure limitation ${ }^{5}$. Moreover, PCV better maintains stability regarding intraoperative ventilatory parameters in patients with concomitant respiratory diseases during laparoscopic cholecystectomy ${ }^{2}$. 
Comparison between volume-controlled and pressure-controlled ventilation ....

\section{METHODS}

After obtaining informed consent from eligible participants, sixty patients scheduled for laparoscopic cholecystectomy have been enrolled in the current prospective, single-blinded, randomized parallel group study. The study was approved by the Ethics Board of Ain Shams University. The inclusion criteria were patients of either sex, aged between 18 and 60 years, of ASA physical status II, diagnosed with COPD, and scheduled for laparoscopic cholecystectomy. Exclusion criteria were patient refusal, inability to maintain stable ventilator settings for $30 \mathrm{~min}$, morbidly obese patients (BMI > $35 \mathrm{~kg} / \mathrm{m} 2$ ), patients with a restrictive type of lung diseases, ASA physical status IV and V and conversion to laparotomy.

All participants underwent complete pre-anaesthetic evaluation. Diagnosis of COPD was confirmed by spirometry, performed at "the Center of Pulmonary Function" at the Chest Department, Ain Shams University Hospital (using Flow screen spirometry, VIASYS, Model 2007). Standard anesthetic technique was performed. Routine continuous monitoring including pulse rate, blood pressure, oxygen saturation, capnometry and electrocardiogram was done throughout the procedure. An arterial access was secured and serial arterial blood samples were drawn for arterial blood gas (ABG) analyses.

Initially, all patients received $\mathrm{VCV}$ with tidal volume of $7 \mathrm{ml} / \mathrm{kg}$ (using ideal body weight), I:E ratio of $1: 2$, respiratory rate $12 \mathrm{breath} / \mathrm{min}$ and fraction of inspired oxygen $\left(\mathrm{FIO}_{2}\right)$ of 0.6 that maintained end-tidal $\mathrm{CO}_{2}$ at $35-40 \mathrm{mmHg}$. Fifteen minutes after creation of pneumoperitoneum, patients were randomized to receive either VCV (Group A) or PCV (Group B). In the PCV group, the ventilator was adjusted so that the preset pressure matched the desired tidal volume (a value of $+5 \%$ was accepted, because PCV allows some variability in tidal volume with changes in impedance) with maximum peak inspiratory pressure of $30 \mathrm{~cm} \mathrm{H}_{2} \mathrm{O}$.

Ethical considerations: The study methodology was reviewed and approved by the Medical Ethics Committee and the Research Review Board of the Anesthesiology, Intensive Care and Pain Management Department, Faculty of medicine, Ain Shams University.
Statistical methods: The collected data were coded, tabulated, revised and statistically analyzed using SPSS program (version 16). Quantitative variables were presented in the form of means and standard deviation. Qualitative variables were presented in form of frequency tables (number and percent). The comparison between quantitative variables was done using t-test. Comparison between qualitative variables was done using Chi square test.

\section{RESULTS}

The study included 60 patients randomized into two groups (30 patients each) according to the ventilation mode (Group $\mathrm{A}=\mathrm{VCV}$, Group $\mathrm{B}=\mathrm{PCV}$ ).

There was no significant difference between study groups as regards demographic profile, COPD duration, and smoking. All study participants were of ASA class II (mild to moderate COPD as confirmed by pulmonary function tests) [Table 1]. The two groups were also comparable in terms of duration of anesthesia, duration of surgery, and duration of $\mathrm{CO} 2$ insufflation [Table 2].

Table (1): Baseline characteristics of the study groups.

\begin{tabular}{|c|c|c|c|c|c|c|}
\hline & \multicolumn{4}{|c|}{ Group } & \multirow{2}{*}{$\begin{array}{l}\text { P- } \\
\text { value }\end{array}$} \\
\hline & & \multicolumn{2}{|c|}{ VCV } & \multicolumn{2}{|c|}{ PCV } & \\
\hline $\begin{array}{l}\text { Age } \\
\text { (Years) }\end{array}$ & Mean \pm SD & \multicolumn{2}{|c|}{$46.600 \pm 5.443$} & \multicolumn{2}{|c|}{$47.200 \pm 6.283$} & 0.694 \\
\hline \multirow{2}{*}{ Sex } & Male & 12 & $40.00 \%$ & 12 & $40.00 \%$ & \multirow{2}{*}{1.000} \\
\hline & Female & 18 & $60.00 \%$ & & $60.00 \%$ & \\
\hline BMI & Mean \pm SD & \multicolumn{2}{|c|}{$27.160 \pm 3.145$} & \multicolumn{2}{|c|}{$27.560 \pm 3.489$} & 0.643 \\
\hline $\begin{array}{l}\text { COPD Duration } \\
\text { (Years) }\end{array}$ & Mean \pm SD & \multicolumn{2}{|c|}{$10.200 \pm 2.605$} & \multicolumn{2}{|c|}{$10.200 \pm 2.605$} & 1.000 \\
\hline \multirow{2}{*}{ Smoking } & No & 18 & 60.00 & 20 & 66.67 & \multirow{2}{*}{0.592} \\
\hline & Yes & 12 & 40.00 & 10 & 33.33 & \\
\hline $\begin{array}{l}\text { Smoking index } \\
\text { (Smokers) }\end{array}$ & Mean \pm SD & \multicolumn{2}{|c|}{$21.000 \pm 2.892$} & \multicolumn{2}{|c|}{$21.200 \pm 2.700$} & 0.870 \\
\hline
\end{tabular}

BMI; Body mass index, COPD; Chronic obstructive pulmonary disease.

Table (2): Duration of surgery, anesthesia, and $\mathrm{CO} 2$ insufflation in study groups.

\begin{tabular}{|l|l|c|c|c|}
\hline \multicolumn{2}{|c|}{} & \multicolumn{3}{c|}{ Group } \\
\cline { 3 - 5 } \multicolumn{2}{|c|}{} & VCV & PCV & P-value \\
\hline $\begin{array}{l}\text { Duration of } \\
\text { anesthesia (min) }\end{array}$ & $\begin{array}{l}\text { Mean } \\
\pm \text { SD }\end{array}$ & $104.600 \pm 3.255$ & $104.400 \pm 3.058$ & 0.807 \\
\hline $\begin{array}{l}\text { Duration of } \\
\text { surgery (min) }\end{array}$ & $\begin{array}{l}\text { Mean } \\
\pm \text { SD }\end{array}$ & $93.200 \pm 3.305$ & $93.800 \pm 3.428$ & 0.493 \\
\hline $\begin{array}{l}\text { Duration of CO2 } \\
\text { insufflation (min) }\end{array}$ & $\begin{array}{l}\text { Mean } \\
\pm \text { SD }\end{array}$ & $68.200 \pm 2.172$ & $69.200 \pm 1.750$ & 0.054 \\
\hline
\end{tabular}

Hemodynamic variables were similar in both groups [Table 3]. End-tidal CO2 (EtCO2) was significantly higher in PCV group (at $35 \mathrm{~min}$.) compared with VCV group [Table 4] 
Table (3): Hemodynamic variables in study groups.

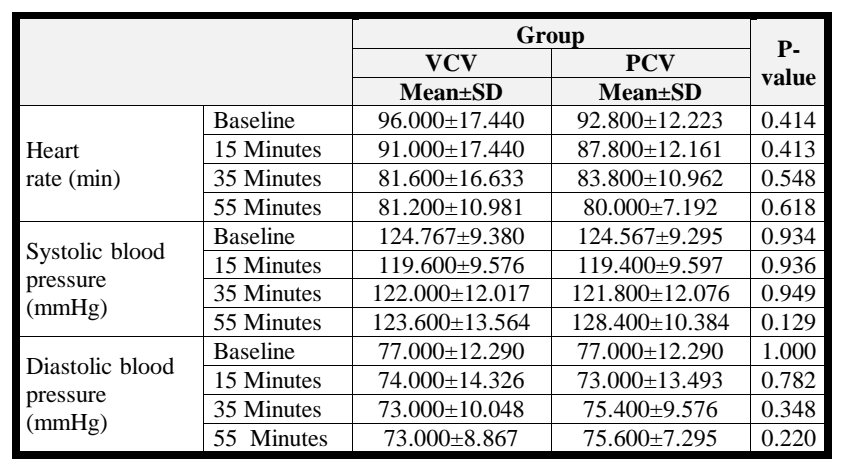

N.B. Time mentioned is counted after creation of pneumoperitoneum.

Table (4): EtCO2 in study groups.

\begin{tabular}{|c|c|c|c|}
\hline \multirow{3}{*}{$\operatorname{EtCO2}(\mathrm{mmHg})$} & \multicolumn{2}{|c|}{ Group } & \multirow{3}{*}{ P-value } \\
\hline & VCV & PCV & \\
\hline & Mean \pm SD & Mean \pm SD & \\
\hline 15 Minutes & $34.500 \pm 3.579$ & $35.233 \pm 1.165$ & 0.290 \\
\hline 35 Minutes & $35.600 \pm 4.360$ & $39.300 \pm 2.575$ & $<0.001 *$ \\
\hline 55 Minutes & $34.833 \pm 1.877$ & $35.500 \pm 4.666$ & 0.471 \\
\hline
\end{tabular}

N.B. Time mentioned is counted after creation of pneumoperitoneum.

As regards ventilatory parameters, there was no significant difference between study groups as regards expiratory tidal volume or minute ventilation. Peak airway pressure (at $35 \mathrm{~min}$. and 55 min.) was significantly lower in PCV group compared with VCV group [Table 5 and Figure 1]. Mean airway pressure (at 55 min.) was significantly higher in PCV group compared with VCV group [Table 6].

Table (5): Peak airway pressure in study groups.

\begin{tabular}{|c|c|c|c|c|}
\hline \multirow{3}{*}{\multicolumn{2}{|c|}{$\begin{array}{c}\text { Peak airway pressure } \\
(\mathrm{cmH2O})\end{array}$}} & \multicolumn{2}{|c|}{ Group } & \multirow{3}{*}{ P-value } \\
\hline & & \multirow{2}{*}{$\frac{\text { VCV }}{\text { Mean } \pm \text { SD }}$} & \multirow{2}{*}{$\begin{array}{c}\text { PCV } \\
\text { Mean } \pm \text { SD }\end{array}$} & \\
\hline & & & & \\
\hline \multicolumn{2}{|c|}{15 Minutes } & $19.400 \pm 5.917$ & $20.000 \pm 0.947$ & 0.585 \\
\hline \multicolumn{2}{|c|}{35 Minutes } & $22.600 \pm 5.986$ & $19.200 \pm 0.997$ & $0.003^{*}$ \\
\hline \multicolumn{2}{|c|}{55 Minutes } & $26.400 \pm 5.556$ & $19.033 \pm 1.098$ & $<0.001 *$ \\
\hline \multicolumn{5}{|c|}{ Trends } \\
\hline \multirow{2}{*}{$\begin{array}{c}15-35 \\
\text { Minutes }\end{array}$} & Differences & $-3.200 \pm 3.242$ & $0.800 \pm 1.095$ & \\
\hline & Paired Test & $<0.001 *$ & $<0.001 *$ & \\
\hline \multirow{2}{*}{$\begin{array}{c}15-55 \\
\text { Minutes }\end{array}$} & Differences & $-7.000 \pm 2.133$ & $0.967 \pm 1.159$ & \\
\hline & Paired Test & $<0.001 *$ & $<0.001 *$ & \\
\hline \multirow{2}{*}{$\begin{array}{c}35-55 \\
\text { Minutes }\end{array}$} & Differences & $-3.800 \pm 3.178$ & $0.167 \pm 1.053$ & \\
\hline & Paired Test & $<0.001 *$ & 0.393 & \\
\hline
\end{tabular}

N.B. Time mentioned is counted after creation of pneumoperitoneum.

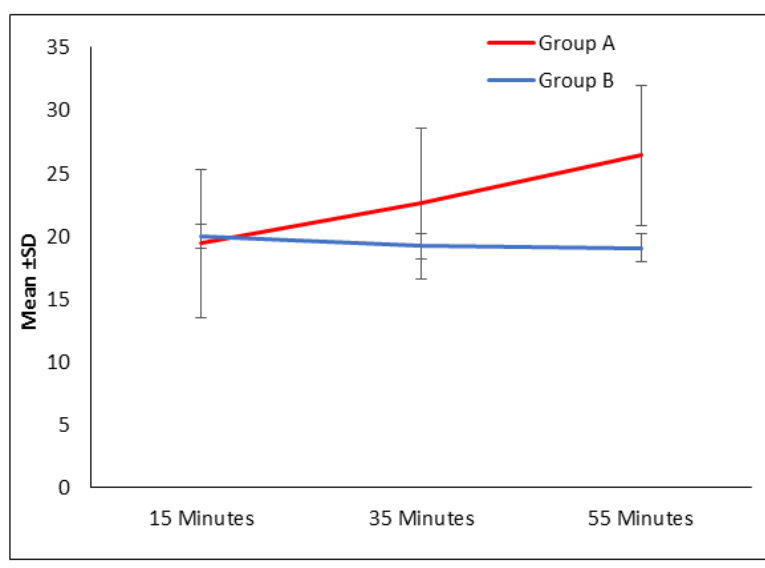

Group A; VCV, Group B; PCV

Figure (1): Peak airway pressure trends in study groups.

Figure (1) showed that VCV group had significant increase in peak airway pressure at 35 and 55 min. In PCV group, conversely, peak airway pressure showed significant decrease at 35 and $55 \mathrm{~min}$.

Table (6): Mean airway pressure in study groups.

\begin{tabular}{|l|c|c|c|}
\hline \multirow{2}{*}{$\begin{array}{c}\text { Mean airway pressure } \\
(\mathbf{c m H 2 O})\end{array}$} & \multicolumn{2}{|c|}{ Group } & \multirow{2}{*}{ P-value } \\
\cline { 2 - 3 } & VCV & PCV & \\
\cline { 2 - 3 } & Mean \pm SD & Mean \pm SD & \\
\hline 15 Minutes & $7.800 \pm 0.761$ & $7.833 \pm 0.791$ & 0.869 \\
\hline 35 Minutes & $9.200 \pm 0.761$ & $9.600 \pm 1.037$ & 0.094 \\
\hline 55 Minutes & $9.400 \pm 0.814$ & $9.800 \pm 0.407$ & $0.019^{*}$ \\
\hline
\end{tabular}

N.B. Time mentioned is counted after creation of pneumoperitoneum.

Serial arterial blood gas analyses revealed that there was no significant difference between study groups as regards $\mathrm{pH}, \mathrm{PaO} 2$, and oxygen saturation $(\mathrm{SpO} 2)$. Patients in PCV group had higher $\mathrm{PaCO} 2$ at 35 min [Table 7].

Table (7): Arterial blood gas analyses in study groups.

\begin{tabular}{|c|c|c|c|c|}
\hline \multirow{3}{*}{\multicolumn{2}{|c|}{ Parameters }} & \multicolumn{2}{|c|}{ Group } & \multirow{4}{*}{$\begin{array}{r}\text { P-value } \\
0.623\end{array}$} \\
\hline & & \multirow{3}{*}{$\begin{array}{c}\text { VCV } \\
\text { Mean } \pm \text { SD } \\
7.400 \pm 0.032\end{array}$} & \multirow{3}{*}{$\begin{array}{c}\text { PCV } \\
\text { Mean } \pm \text { SD } \\
7.397 \pm 0.018\end{array}$} & \\
\hline & & & & \\
\hline \multirow{3}{*}{$\mathrm{pH}$} & 15 Minutes & & & \\
\hline & 35 Minutes & $7.390 \pm 0.032$ & $7.380 \pm 0.015$ & 0.137 \\
\hline & 55 Minutes & $7.396 \pm 0.034$ & $7.383 \pm 0.016$ & 0.060 \\
\hline \multirow{3}{*}{$\mathrm{PaO} 2$} & 15 Minutes & $209.800 \pm 15.078$ & $205.533 \pm 10.401$ & 0.207 \\
\hline & 35 Minutes & $212.300 \pm 24.993$ & $204.467 \pm 3.910$ & 0.095 \\
\hline & 55 Minutes & $200.200 \pm 20.458$ & $204.200 \pm 17.061$ & 0.414 \\
\hline \multirow{3}{*}{$\mathrm{PaCO} 2$} & 15 Minutes & $38.800 \pm 3.305$ & $39.200 \pm 0.761$ & 0.521 \\
\hline & 35 Minutes & $39.400 \pm 4.438$ & $41.800 \pm 2.524$ & $0.013^{*}$ \\
\hline & 55 Minutes & $38.800 \pm 1.972$ & $38.000 \pm 4.639$ & 0.388 \\
\hline \multirow{3}{*}{$\mathrm{SpO} 2$} & 15 Minutes & $100.000 \pm 0.000$ & $100.000 \pm 0.000$ & 1.000 \\
\hline & 35 Minutes & $100.000 \pm 0.000$ & $100.000 \pm 0.000$ & 1.000 \\
\hline & 55 Minutes & $99.800 \pm 0.407$ & $99.800 \pm 0.407$ & 1.000 \\
\hline
\end{tabular}

\section{DISCUSSION}

Chronic obstructive pulmonary disease is a well-known independent risk factor for the development of postoperative pulmonary and 
cardiac complications after thoracic or non-thoracic surgery ${ }^{1}$. Several ventilatory strategies have been proposed to prevent intraoperative atelectasis and improve arterial oxygenation in laparoscopic surgeries but they remain controversial ${ }^{7}$.

As for hemodynamic variables, there was no significant difference between study groups. When switching from VCV to PCV ventilation, the cardiovascular effects of PCV should be related to airway pressure, through its effects on pleural pressure ${ }^{8}$. In the current study, PCV was not associated with significant hemodynamic effects. One plausible explanation is the absence of a significant increase in intrathoracic pressure after an increase in mean airway pressure ${ }^{9}$.

The main finding in the current study was decreased peak airway pressure in PCV group when compared with VCV group; associated with increased mean airway pressure in PCV group more than VCV group. Tidal volume and minute ventilation were comparable in both groups.

When compared with VCV, the association between PCV and a lower peak airway pressure was a constant finding in previous studies 9. Reduction in peak airway pressure with PCV is a previously well-documented finding in other conditions, including acute lung injury/acute respiratory distress syndrome ${ }^{10}$ and during onelung ventilation ${ }^{11}$.

This constant finding can be explained by the decelerating inspiratory flow pattern, also known as descending ramp, with the maximum value reached early in inspiration, then followed by a deceleration of the flow rate, resulting in its characteristic form. The peak airway pressure is limited; thus reducing the risk of barotrauma. The initial rapid flow leads to early alveolar inflation; a constant inspiratory pressure is then maintained in alveoli thereby improving ventilation in alveoli with variable time constant ${ }^{12}$.

A decelerating flow waveform pattern also has been shown to increase mean airway pressure. Although increasing an airway pressure seems to be detrimental, mean airway pressure correlates closely with improved lung inflation and oxygenation. Patients receiving mechanical ventilation with a decelerating flow waveform pattern and increases in mean airway pressure have shown an improvement in gas distribution and oxygenation ${ }^{13}$.
The higher mean airway pressure seen in PCV is mostly a result of lengthening the inspiratory time (which is the time over which the tidal volume is delivered or the pressure is maintained depending on the mode of ventilation). This improves oxygenation; as it allows redistribution of gas from more compliant alveoli to less compliant alveoli ${ }^{14}$.

Conversely, the VCV mode utilizes a constant flow to deliver a target tidal volume that ensures satisfactory minute ventilation. In patients with decreased lung compliance, this will result in an increased peak airway pressure, and a higher tidal volume is required to maintain minute ventilation. This will cause alveolar over distension, leading to lung injury in the form of volutrauma and barotrauma ${ }^{15}$.

As regards arterial blood gas analyses, there was no significant difference between study groups as regards $\mathrm{pH}, \mathrm{PaO}_{2}$ and $\mathrm{SpO}_{2}$. Both $\mathrm{PCV}$ and $\mathrm{VCV}$ were effective in maintaining adequate oxygenation. Noteworthy, increase in mean airway pressure appeared to be directly related to increase in oxygenation ${ }^{16}$. However, the small magnitude of the change in mean airway pressure, although statistically significant, possibly have minimized its positive effect on oxygenation and thus failed to affect gas exchange significantly. Another possible explanation of the current findings (i.e., PCV did not improve the saturation parameters and oxygenation, relative to the conventional $\mathrm{VCV}$ ) is that no mechanical ventilation mode was applied with a positive end expiratory pressure (PEEP).

Monitoring end-tidal $\mathrm{CO}_{2}\left(\mathrm{EtCO}_{2}\right)$ is an adequate guide for determining the minute ventilation required to maintain normocarbia, and it provides a reasonable approximation of $\mathrm{PaCO}_{2}$ in healthy patients undergoing laparoscopic cholecystectomy ${ }^{17}$. After pneumoperitoneum, it takes about 15 min for $\mathrm{PaCO}_{2}$ to reach a plateau ${ }^{18}$. Thus, in the current study, arterial blood samples were taken for analysis $15 \mathrm{~min}$ after the establishment of pneumoperitoneum.

$\mathrm{EtCO}_{2}$ was significantly higher (yet not clinically significant) in PCV group (at $35 \mathrm{~min}$ ) compared with VCV group; then returned to nonsignificant difference (at $55 \mathrm{~min}$ ) compared with VCV group. Concomitantly, patients in PCV group had higher $\mathrm{PaCO}_{2}$ (yet not clinically significant) at 35 min, compared with VCV group. 
Many studies confirmed the results of the present study that PCV group is associated with decreased peak airway pressure and increased mean airway pressure when compared to VCV group. For instance, Surbatović and colleagues ${ }^{2}$, compared the effects of intermittent positive pressure ventilation (IPPV) and PCV on respiratory function in 60 patients with ASA III with concomitant respiratory diseases undergoing laparoscopic cholecystectomy, and found that there was a significant decrease of peak inspiratory pressure during $\mathrm{PCV}$ compared to $\mathrm{VCV}$ in three time intervals following pneumoperitoneum without significant differences in tidal volume. Without adding PEEP, these results also agreed with current results when no statistically significant differences were found in $\mathrm{SpO}_{2}$ or $\mathrm{PaO}_{2}$ values neither within nor between the two groups. Also $\mathrm{pH}$ values did not show significant difference among groups. In that study, $\mathrm{EtCO}_{2}$ were also significantly higher in the PCV group when compared to VCV group in the time intervals after pneumoperitoneum.

Similarly, Mihalj and colleagues ${ }^{19}$ also came to the same conclusion in a study included 60 non obese patients aged between 18 and 70 years with ASA score I-III, and without prior history of chronic respiratory diseases, who were scheduled for laparoscopic cholecystectomy. Peak airway pressure was significantly higher in VCV group. Mean airway pressure was higher in PCV group of patients. Despite PEEP of $7 \mathrm{~cm} \mathrm{H}_{2} \mathrm{O}$ was added to both of the groups and anesthesia was maintained with a gas mixture of $\mathrm{O}_{2}(40 \%)$ and $\mathrm{N}_{2} \mathrm{O}(60 \%)$, the values of $\mathrm{SpO}_{2}$ were within the normal range with no major differences.

The current results were also in accordance with the meta-analysis done by Wang and colleagues 20 , who recruited eight randomized controlled trials comparing the effects of PCV and VCV on respiratory and hemodynamic parameters during laparoscopic surgery; with a total of 428 participants (214 cases using PCV and 214 cases using VCV). In that meta-analysis, PCV was associated with significantly lower peak airway pressure. Also PCV was associated with significantly higher mean airway pressure. It was also concluded that the $\mathrm{EtCO}_{2}$ tension increases significantly in PCV compared with VCV.

The results of the current study also agree with Gupta and colleagues ${ }^{21}$ who compared VCV with PCV regarding maintenance of oxygenation in 102 obese patients undergoing laparoscopic cholecystectomy. Peak airway pressures were significantly lower in PCV than that in $\mathrm{VCV}$. Opposing current results, significantly higher $\mathrm{PO}_{2}$ levels in those who received $\mathrm{PCV}$ were found compared with those who received VCV. This can be explained by the fact that large tidal volume in VCV mainly ventilates the non-dependent portion of the lung, leading to excessive stretching of those regions without improving the overall ventilation 22. On the contrary, in PCV, recruitment of collapsed alveoli due to high flow rate in the early inspiratory phase leads to improved lung ventilation. Although the delivery of tidal volume and minute ventilation were lower in PCV, adequate $\mathrm{CO}_{2}$ elimination was achieved due to overall improvement in lung ventilation ${ }^{5}$.

This also coincides with a study done by Tyagi and colleagues ${ }^{23}$ who randomized 42 non obese patients with ASA I and II physical status, undergoing laparoscopic cholecystectomy, to receive either PCV or VCV. A significant increase in peak inspiratory pressure was found in VCV group compared to PCV group. Conversely, the mean airway pressure was significantly increased in the PCV group compared with the VCV group. In that unique study, invasive cardiac output monitoring and cardiac index were used to compare hemodynamic effects. Despite a significant increase in the mean airway pressure with PCV, no significant changes in hemodynamic variables observed in that study. There was no difference between the two groups in $\mathrm{PaO}_{2}$ (despite that PEEP was added to both groups) or indices of carbon dioxide elimination, i.e. minute ventilation requirement or $\mathrm{PaCO}_{2}$.

Also in accordance with current results, Balick-Weber and colleagues ${ }^{9}$ enrolled 21 patients undergoing laparoscopic urological surgery in a cross-over study comparing VCV versus PCV regarding hemodynamic consequences as a main finding using transesophageal echocardiography. Lower peak inspiratory pressure was observed during PCV compared to VCV. Mean airway pressure was significantly increased with PCV. It was noted that both PCV and VCV were associated with statistically similar hemodynamic consequences. Despite a significant, although small increase in mean airway pressure with PCV compared with VCV, no echocardiographic 
changes were noted. Without adding external PEEP, and in agreement with current results, no significant difference was found in arterial oxygenation between VCV and PCV modes.

On the other hand, the results of the present study were not in accordance with some other studies. For instance, Aydin and colleagues ${ }^{24}$ compared PCV and VCV modes (with PEEP added to both groups) in 70 patients (ASA scores I-II) undergoing laparoscopic cholecystectomy. Peak pressure values did not differ significantly between the two groups. $\mathrm{EtCO}_{2}, \mathrm{PaO}_{2}, \mathrm{PaCO}_{2}$ and oxygenation index values were not significantly different, but alveolar arterial oxygen gradient after pneumoperitoneum were found to be significantly higher in PCV group than in VCV group. Also it was noted that after pneumoperitoneum, lung compliance decreased in both groups, more importantly in PCV. According to authors, these results may suggest that VCV mode can provide better alveolar ventilation during laparoscopic cholecystectomy. In that study, $\mathrm{FIO}_{2}$ was kept constant at $50 \%$ in both groups. So the higher alveolar-arterial oxygen gradient in PCV can be explained by the variable tidal volume during PCV ventilation. Authors hypothesized that low tidal volumes in PCV can cause a reduction in the compliance of the lungs and intra-operative atelectasis can occur after insufflation.

\section{CONCLUSIONS}

PCV and VCV were generally effective in maintaining adequate ventilation, oxygenation and hemodynamic stability in study groups. Comparison of both modes of ventilation showed some particular advantages of PCV. Peak airway pressure was significantly lower in PCV group compared with VCV group, thus decreasing the risk of barotrauma. PCV may a better choice than VCV in COPD patients undergoing laparoscopic cholecystectomy because of its advantages. It particularly decreases the risk of barotrauma in these patients thus limits the chance of lung injury.

\section{LIMITATIONS}

There had been some limitations in the present study. First, COPD patients with ASA II physical status only were included; as candidate participants with more advanced disease were not found in the study period. Second, sample size may not be able to detect minor differences in some studied variables. Third limitation is the lack of direct measure of lung compliance and plateau pressure which needs equipped anesthesia workstation with inspiratory and expiratory hold maneuvers.

\section{Declaration of Conflicting Interests}

The author declared no conflicts of interest with respect to the authorship and/or publication of this article.

\section{REFERENCES}

1. Atalay F, Uygur F, Cömert $M$ et al. (2011): Postoperative complications after abdominal surgery in patients with chronic obstructive pulmonary disease. Turk J Gastroenterol., 22(5):523-8.

2. Surbatović M, Vesić Z, Djordjević D et al. (2013): Effect of mechanical pressurecontroled ventilation in patients with disturbed respiratory function during laparoscopic cholecystectomy. Vojnosanit Pregl.,70(1):9-15.

3. Sharma KC, Brandstetter RD, Brensilver JM et al. (1996): Cardiopulmonary physiology and pathophysiology as a consequence of laparoscopic surgery. Chest, 110:810-815

4. Sprung J, Whalley DG, Falcone $T$ et al. (2002): The impact of morbid obesity, pneumoperitoneum, and posture on respiratory system mechanics and oxygenation during laparoscopy. Anaesth Analg., 94: 1345-1350.

5. Nichols D, Haranath S (2007): Pressure control ventilation. Crit Care Clin., 23:183-99.

6. Hong JY, Chung KH, Lee YJ (1999): The changes of ventilator parameters in laparoscopic colecystectomy. Yonsei Med J., 40:307-312

7. Cadi P, Guenoun T, Journois D et al. (2008): Pressure-controlled ventilation improves oxygenation during laparoscopic obesity surgery compared with volume-controlled ventilation. Br J Anaesth., 100:709-716.

8. Pinsky MR (2002): Recent advances in the clinical application of heart- lung interactions. Curr Opin Crit Care, 8: 26-31

9. Balick-Weber CC, Nicolas P, HedrevilleMontout $M$ et al. (2007): Respiratory and haemodynamic effects of volume - controlled versus pressure-controlled ventilation during laparoscopy: a cross-over study with echocardiographic assessment. British Journal of Anaesthesia, 99: 429-35 
10. Davis K Jr, Branson RD, Campbell RS et al. (1996): Comparison of volume control and pressure control ventilation: is flow waveform the difference? Journal of Trauma, 41: 808-14.

11. Unzueta MC, Casas JI, Moral MV (2007): Pressure-controlled versus volume-controlled ventilation during one-lung ventilation for thoracic surgery. Anesthesia and Analgesia, 104: 1029-33.

12. Edibam C, Rutten AJ, Collins DV et al. (2003): Effect of inspiratory flow pattern and inspiratory to expiratory ratio on nonlinear elastic behavior in patients with acute lung injury. American Journal of Respiratory and Critical Care Medicine, 167: 702-7.

13. Shelledy DC, Peters JI (2003): Initiating and adjusting ventilatory support. In: Wilkins RL, Stroller JK, Kacmarek RM. Egan's Fundamentals of Respiratory Care. 8th ed. St Louis: Mosby Elsevier.

14. Armstrong BW Jr, Maclntyre NR (1995): Pressure-controlled, inverse ratio ventilation that avoids air trapping in the adult respiratory distress syndrome. Critical Care Medicine, 23: 279-85.

15. Koh SO (2007): Mode of mechanical ventilation: Volume controlled mode. Crit Care Clin., 23: 161-7.

16. Marini JJ, Ravenscraft SA (1992): Mean airway pressure: physiologic determinants and clinical importance. Part II. Clinical implications. Crit Care Med.,20: 1604-16

17. Cunningham AJ, Nolan C (2006): Anesthesia for Minimally Invasive Procedures, Clinical Anesthesia. 5th ed. Barash PG, Cullen BF, Stoelting RK and editors. Philadelphia: Lippincott Williams and Wilkins, pp. 1061-71.

18. Joris JL (2005): Anesthesia for Laparoscopic Surgery, Miller's Anesthesia, 6th ed. In: Miller RD, Editor. Philadelphia: Elsevier Churchill Livingstone.

19. Mihalj M, Vladić D, Karlović Z et al. (2017): Effects of pressure controlled and volume controlled ventilation on hemodynamic and respiratory parameters in patients during laparoscopic cholecystectomy. Acta Clin Croat., 56:555-560

20. Wang JP, Wang HB, Liu YJ et al .(2015): Comparison of Pressure- and VolumeControlled Ventilation in Laparoscopic Surgery: A Meta-analysis of Randomized Controlled Trial. Clin Invest Med., 38(3):E119-41.
21. Gupta SD, Kundu SB, Ghose T et al. (2012): A comparison between volume-controlled ventilation and pressure-controlled ventilation in providing better oxygenation in obese patients undergoing laparoscopic cholecystectomy. Indian J Anaesth.,56: 276-282.

22. Marino PL, Sutin KM and Editors (2007): Principles of Mechanical Ventilation, The ICU Book, 3rd ed. In. Philadelphia: Lippincott Williams and Wilkins.

23. Tyagi A, Kumar R, Sethi AK et al. (2011): A comparison of pressure-controlled and volumecontrolled ventilation for laparoscopic cholecystectomy. Anaesthesia, 66: 503-508.

24. Aydin V, Kabukcu HK, Sahin N et al. (2016): Comparison of pressure and volumecontrolled ventilation in laparoscopic cholecystectomy operations. Clin Respir J., 10(3):342-9. 